\title{
Regulation of Chemokine Expression in the Tumor Microenvironment
}

\author{
Anton V. Gorbachev ${ }^{1, *}$, Robert L. Fairchild ${ }^{1,2,3}$ \\ ${ }^{1}$ Department of Immunology, Cleveland Clinic, Cleveland, OH, 44195 \\ ${ }^{2}$ Glickman Urological Institute, Cleveland Clinic, Cleveland, $\mathrm{OH}, 44195$ \\ ${ }^{3}$ Department of Pathology, Case Western Reserve University School of Medicine, Cleveland, $\mathrm{OH}$, \\ 44106
}

\begin{abstract}
Chemokines are chemotactic cytokines critical for homeostatic and inflammation-induced trafficking of leukocytes during immune responses, hematopoesis, wound healing, and tumorigenesis. Despite three decades of intensive study of the chemokine network, the molecular mechanisms regulating chemokine expression during tumor growth are not well understood. In this review, we focus on the role of chemokines in both tumor growth and antitumor immune responses and on molecular mechanisms employed by tumor cells to regulate chemokine expression in the tumor microenvironment. Multiple mechanisms used by tumors to regulate chemokine production, including those revealed by very recent studies (such as DNA methylation or post-translational nitrosylation of chemokines) are discussed. Concluding the review, we discuss how understanding of these regulatory mechanisms can be used in cancer therapy to suppress tumor growth and/or to promote immune-mediated eradication of tumors.
\end{abstract}

\section{Keywords}

chemokines; tumorigenesis; cancer therapy

\section{INTRODUCTION}

Chemokines are small-molecular-weight cytokines that mediate leukocyte trafficking through chemotaxis. Chemotactic signals of chemokines are mediated through $\mathrm{G}$ proteincoupled receptors expressed on target cells. Chemokines contain two or four cysteine residues in conserved regions of the molecule and can be structurally divided into four subclasses based on the location and spacing of two $\mathrm{NH}_{2}$-terminal cysteine residues: $\mathrm{CC}$, $\mathrm{CXC}, \mathrm{CX} 3 \mathrm{C}$, and $\mathrm{C}$ chemokines. According to this classification, $\mathrm{G}$ protein-coupled chemokine receptors binding to each subclass of chemokine family are distinguished as CCR, CXCR, CX3CR, and XCR receptor groups. ${ }^{1,2}$

*Address all correspondence to: Anton V. Gorbachev; Department of Immunology, Cleveland Clinic, NB3-30 9500 Euclid Ave, Cleveland, OH, 44195, orca44124@yahoo.com. 
Being potent chemoattractants, chemokines play a critical role in the induction and elicitation of immune responses by orchestrating leukocyte trafficking within lymphoid tissues and to sites of inflammation. ${ }^{3-5}$ Furthermore, chemokines affect the functions of nonimmune cells such as fibroblasts and endothelial, smooth muscle, and tumor cells, influencing many important physiologic or pathologic events, such as hematopoiesis and angiogenesis, during tissue repair or tumor growth, and collagen production during fibrosis. 4,6,7 Recent studies have also indicated that certain chemokines influence priming and activation or differentiation of antigen-specific $\mathrm{T}$ cells acting as costimulatory cytokines during the initiation of immune responses. ${ }^{8-10}$

Functionally, chemokines are distinguished as homeostatic or inflammatory based on their pattern of expression and physiological function. Homeostatic chemokines are constitutively expressed in tissues and maintain basal leukocyte homing and circulation in lymphoid organs and peripheral tissues. ${ }^{2}$ Examples of homeostatic chemokines are CCL14, CCL19, CCL20, CCL21, CXCL12, and CXCL13 chemokines. In contrast, inflammatory chemokines are induced by various signals such as proinflammatory cytokines (e.g., IL-1, TNF, IFNs) or danger signals (e.g., release of heat shock proteins or signaling through toll-like receptors) in response to infection, tissue injury, or developing malignancy. Inflammatory chemokines facilitate the activation and recruitment of leukocytes during immune responses. ${ }^{2,11}$ Examples of inflammatory chemokines include CCL2, CCL3, CCL4, and CCL5 chemokines; the neutrophil chemoattractant CXCL8 or Th1 cell and NK cell chemoattractants CXCL9, CXCL10 and CXCL11. ${ }^{12,13}$ In addition to the recruitment of various leukocyte populations into lymphoid organs and sites of inflammation, inflammatory chemokines regulate the proliferation of endothelial cells, expression of enzymes involved in tissue remodeling (e.g., metalloproteases), and co-stimulation or differentiation of $\mathrm{T}$ cells to different functional subsets. ${ }^{12}$ The expression of certain homeostatic chemokines, such as CCL20, can be up-regulated during inflammation and may also function as inflammatory mediators during immune responses. Therefore, inflammatory chemokines are important for both induction and elicitation of immune responses, and their expression must be tightly regulated to prevent excessive immune responses that lead to chronic inflammation and pathologic injury of tissues.

Many chemokines and their receptors are redun-dant; that is, most chemokine receptors interact with several ligands (e.g., CXCR2 expressed on neutrophils that binds CXCL1, CXCL2, CXCL3, CXCL5, CXCL6, CXCL7, and CXCL8 chemokines or CXCR3 that binds CXCL4, CXCL4L1, CXCL9, CXCL10, and CXCL11 chemokines). ${ }^{5,12}$ Conversely, many chemokines bind to multiple receptors, such as CXCL6 and CXCL8, activating CXCR1 and CXCR2 receptors. More recent studies have revealed even greater complexity of the chemokine network by demonstrating that different chemokine ligands may provide distinct downstream signals upon engagement of the same chemokine receptor. ${ }^{14,15}$ Furthermore, some chemokine receptors, such as CXCR3, exist in several isoforms that can provide distinct signals upon binding the chemokine ligand. In the case of CXCR3, its CXCR3A isoform activates cell migration and proliferation, while the CXCR3B variant of CXCR3 provides the signal-inhibiting cell proliferation. ${ }^{16-18}$ 
Overall, chemokines and their receptors are critical for virtually any kind of immune response, including immune responses to malignant tumors. Because of the complexity of the chemokine network, many characteristics, such as induction, regulation, and consequences of chemokine expression and signaling during tumor growth and evolution under immune stress, remain incompletely defined. The important role of chemokines in the regulation of anti-tumor immunity implicates them as attractive therapeutic targets that can be used to manipulate the immune response involved in cancer. This review focuses on mechanisms that regulate chemokine expression in tumors and on potential therapeutic applications of our knowledge of chemokine regulation.

\section{DUAL ROLE OF CHEMOKINES IN TUMOR BIOLOGY}

\section{A. Overview}

To grow in the host, malignant cells create a microenvironment that promotes their growth and simultaneously protects them from destruction mediated by host's immunity. The tumor microenvironment contains various types of non-malignant cells such as stromal cells, fibroblasts and tumor-infiltrating leukocytes secreting a wide variety of bioactive molecules (i.e., growth factors, enzymes, cytokines, and chemokines). These bioactive factors influence tumor growth via multiple mechanisms, including angiogenesis, digestion of tissues surrounding the tumor or recruitment of cells, that either promote or suppress tumor growth. ${ }^{19}$ Chemokines significantly contribute to shaping the tumor microenvironment as they play a dual role in tumor development. Based on many studies in both mice and humans, chemokines can be divided into three categories regarding their role in malignant growth (Table 1). Tumor-promoting (pro-tumor) chemokines have been shown to facilitate growth of different cancers. These chemokines include CXCL1, CXCL2, and CXCL3, CXCL5, CXCL6, CXCL7, CXCL8, and CXCL12, which induce the migration of endothelial cells or their precursors into the tumor microenvironment to form blood vessels and ensure an abundant supply of blood and nutrients to the rapidly growing tumor. ${ }^{12,13,20}$ Other examples of tumor-promoting chemokines are CCL1 and CCL28, which mediate suppression of antitumor immunity through recruiting immunoregulatory cells (e.g., FoxP3 ${ }^{+}$regulatory $\mathrm{T}$ cells or Tregs and myeloid-derived suppressor cells or MDSC) into tumors. ${ }^{12,21}$ Anti-tumor chemokines act as antagonists of pro-tumor chemokines by directly inhibiting angiogenesis (i.e., CXCL9, CXCL10, CXCL11 and CXCL4, CXCL4L1 chemokines), recruiting effector cytolytic T cells (CTL) and NK cells into the tumor (i.e., CXCL9, CXCL10, CXCL11, CXCL16, and CX3CL1), or promoting the activation of tumor-specific T cells through the recruitment of tumor antigen-presenting dendritic cells (DCs) into T-cell priming sites (i.e., CCL19, CCL21). ${ }^{12,20} \mathrm{~A}$ third group of chemokines can exert both pro-tumor and anti-tumor properties depending on the type of cancer and/or stage of tumor growth. CCL3, CCL4, and CCL5 facilitate anti-tumor immunity by recruiting CCR5-expressing effector $\mathrm{T}$ cells into the tumor; however, in pancreatic cancer, CCL5 attracts CCR5 ${ }^{+}$FoxP3 ${ }^{+}$Tregs rather than effector cells and promotes immunosuppression of anti-tumor immune responses. ${ }^{22}$ CCL17, CCL19, CCL20, CCL21, and CCL22 mediate tumor antigen-presenting DC trafficking between the tumor and draining lymph nodes and may also act as costimulatory cytokines to promote the activation of tumor-specific T cells. ${ }^{8,23-25}$ On the other hand, CCL21 can 
recruit FoxP $3{ }^{+}$Tregs or MDSC in melanoma, ${ }^{26}$ while CCL20 and CCL22 expression in ovarian and breast cancers correlates with the recruitment of FoxP3 ${ }^{+}$Tregs. ${ }^{27-29}$

\section{B. CXC and CX3C Chemokines}

CXC chemokines can be subdivided into $\mathrm{ELR}^{+}$and $\mathrm{ELR}^{-}$chemokines based on the presence or absence of an ELR motif (cluster of Glu-Leu-Arg amino acids). ELR ${ }^{+}$ chemokines CXCL1, CXCL2, CXCL3, CXCL5, CXCL6, CXCL7, and CXCL8 (IL-8) are similar in structure and function. These chemokines signal through CXCR1 and/or CXCR2 expressed on endothelial cells and certain populations of tumor-infiltrating leukocytes such as neutrophils and MDSCs. ELR ${ }^{+}$chemokines promote tumor angiogenesis either directly through inducing the migration of endothelial cells to form new blood vessels (neovascularization) or indirectly through recruiting neutrophils or MDSCs producing proangiogenic factors (e.g., VEGF, MMPs). ${ }^{30-34}$ Another pro-angiogenic CXC chemokine, CXCL12, enhances angiogenesis by recruiting CXCR4-expressing endothelial progenitor cells from bone marrow into the tumor microenvironment or by recruiting MDSCs producing endothelial cell growth factor VEGF. ${ }^{35,36}$ CXCL12 also promotes tumor metastasis through recruitment of CXCR4-expressing tumor cells into the tissues producing this chemokine. ${ }^{36}$ Whereas most ELR ${ }^{+} \mathrm{CXC}$ chemokines promote tumor growth by enhancing angiogenesis or by recruiting suppressor cells (MDSC, M2 type macrophages), ELR $^{-}$ligands of CXCR3, CXCL9, CXCL10, and CXCL11 inhibit the growth of many tumors. First, these chemokines and two other CXCR3 ligands, CXCL4 and CXCL4L1, act as angiostatic factors by directly inhibiting endothelial cell proliferation. ${ }^{5,37,38}$ Second, CXCR3 chemokines CXCL9, CXCL10, and CXCL11 recruit CXCR3-expressing effector Th1 cells, and NK cells into the tumor, promoting immune-mediated destruction of tumor cells. ${ }^{39-42}$ A considerable number of clinical studies have correlated the expression of CXCR3 chemokines in tumors with increased infiltration of $\mathrm{T}$ and/or NK cells and favorable clinical outcome in several different human cancers. ${ }^{43-47}$ Other CXC chemokines with potent anti-tumor activity are CXCL14 and CXCL16. CXCL14 is constitutively expressed in normal tissues; however, its expression is down-regulated in many cancers. ${ }^{48-50}$ CXCL14 inhibits angiogenesis by blocking the chemotaxis of endothelial cells. ${ }^{49}$ CXCL16 recruits activated CXCR6-expressing T and NK cells into tumors, and the expression of this chemokine has been correlated with favorable prognosis in human renal cancer. ${ }^{51,52}$

The only known member of the CX3C chemokine family is CX3CL1 chemokine or fractalkine. Fractalkine expression in neuroblastoma and colorectal cancer has been correlated with increased numbers of tumor-infiltrating CD4 and CD8 T cells and with better patient survival. ${ }^{53}$

\section{CC Chemokines}

Whereas CXC chemokines affect tumor growth by modulating angiogenesis and/or recruitment of effector or regulatory immune cells, CC chemokines influence tumor growth mostly through the recruitment of immune cells into tumors. CCL1 and CCL28 recruit FoxP $3^{+}$regulatory $\mathrm{T}$ cells (Tregs) that, in turn, suppress effector functions of tumorinfiltrating CTL. ${ }^{54,55}$ Other CC chemokines such as CCL5, CCL17, CCL21, and CCL22 can also function as chemoattractants of Tregs in certain cancers. ${ }^{21,27-29}$ It appears that Tregs 
express a wide variety of CCR chemokine receptors (e.g., CCR5, CCR4, CCR7, CCR8, and CCR10) and respond to ligands of these receptors. ${ }^{21}$ It is likely that inflammatory conditions in the microenvironment of each particular type of cancer determine what CCL chemokine/ receptor signal is used by Tregs to infiltrate tumors. CCL2 is expressed in many solid cancers and is known as a potent attractant of MDSC and tumor-associated macrophages (TAM) with the M2 immuno-regulatory phenotype ${ }^{56,57}$ Accumulation of these cells in tumors leads to tumor progression through multiple mechanisms including angiogenesis, invasion of tumor cells into surrounding tissues, and suppression of effector T and NK cell functions. Results of studies in a mouse model of colon cancer indicate that CCL2 is able to promote intra-tumor recruitment of effector $\mathrm{CD} 8 \mathrm{~T}$ cells mediating tumor regression. ${ }^{58}$ Many other CC chemokines play a dual role in tumor development. CCL4 and CCL5 can recruit CCR5-expressing Tregs, but they are also able to attract $\mathrm{CCR}^{+}$effector $\mathrm{T}$ cells into tumors. ${ }^{22,59}$ In a mouse model of melanoma, CCL5 synergizes with CXCL9 and CXCL10 chemokines to mediate intra-tumor recruitment of both $\mathrm{CCR}^{+}{ }^{+}$and $\mathrm{CXCR} 3^{+}$effector $\mathrm{T}$ cells in numbers sufficient to suppress tumor growth. ${ }^{59}$ Chemokines CCL17, CCL19, CCL20, and CCL21 are critical for the induction of tumor-specific T-cell-mediated immune responses by directing the migration of tumor antigen-presenting DC into draining lymph nodes and by facilitating the engagement of these DC and tumor-specific T cells. ${ }^{23-25}$ CCL19 and CCL21 also act as costimulatory cytokines during priming of tumor-specific T cells. ${ }^{8,60}$ Furthermore, these chemokines contribute to the formation of tertiary lymphoid structures (TLS), inflammation-induced lymphoid aggregates that develop outside of secondary lymphoid organs and may serve as additional activation sites for tumor-reactive $\mathrm{T}$ and B cells. ${ }^{61,62}$ The presence of TLS in tumors has been associated with prolonged survival of cancer patients. ${ }^{61}$ CCL19 and CCL21 guide CCR7-expressing DC and T cells into TLS and promote the activation of tumor-reactive $\mathrm{T}$ cells within the tumor. However, these chemokines are also able to support an immunosuppressive tumor microenvironment by recruiting CCR7-expressing Tregs and/or MDSC into tumors or TLS. ${ }^{27,55}$

In addition to creating either tumor-suppressing conditions (e.g., recruitment of effector $\mathrm{T}$ cells, form ation of TLS) or tumor-promoting conditions (e.g., recruitment of Tregs, M2type macrophages or MDSC) in the tumor microenvironment, some CC chemokines promote tumor expansion by mediating tumor cell invasion or migration to distant sites. Recent studies in both mice and humans have shown that CCL1 is critical for metastasis formation in tumor-draining lymph nodes by recruiting CCR8-expressing melanoma or breast carcinoma cells into lymph nodes. ${ }^{63}$

Therefore, the role of chemokines in tumor biology and in anti-tumor immune responses is very complex, as many chemokines are capable of exerting both pro-tumor and anti-tumor effects by signaling through receptors that can be expressed by both effector and regulatory immune cells. However, studies in mice and humans suggest that manipulating the chemokine network by inhibiting the expression and/or signaling of pro-tumor chemokines and enhancing intra-tumor expression of certain chemokines that promote anti-tumor immunity rather than tumor growth is a promising approach in cancer immunotherapy. 


\section{REGULATION OF CHEMOKINE EXPRESSION AND FUNCTION IN THE TUMOR}

To prevent excessive tissue inflammation and damage during immune responses, the expression and functions of chemokines involved in these responses must be tightly regulated. The induction of proinflammatory chemokines usually occurs in response to stimulation of immunity through the NF-kB pathway, which is triggered by various danger signals released as a consequence of tissue injury and/or stress or infection. ${ }^{64}$ Timely downregulation of chemokine expression during declining immune responses is mediated through multiple mechanisms including modulation of chemokine mRNA stability, atypical chemokine receptors (decoy receptors), or post-translational modification of chemokine molecule by various enzymes. ${ }^{65}$ Regulation of chemokine mRNA stability is an important immunoregulatory mechanism, as the mRNA encoding many chemokines is unstable and prone to degradation by nucleases. This regulation is mediated through the binding of regulatory factors to AU-rich elements (ARE) of the 3'-untranslated region. Such AREbinding regulatory factors are induced by pro-inflammatory cytokines released during the induction and/or elicitation of immune response (IL-1 or IL-17) to increase stability of chemokine mRNA upon binding to ARE sites. In contrast, anti-inflammatory cytokines, such as IL-4 or IL-10, decrease mRNA stability of inflammatory chemokines and downregulate their expression through this mechanism. ${ }^{66-69}$ Decoy chemokine receptors bind to chemokines but are unable to provide G-protein-dependent signaling, acting as antagonists of classical chemokine receptors and decreasing the availability of chemokines for these receptors. ${ }^{65}$ Degradation or cleavage of chemokines by enzymes such as peptidases CD13 or CD26 or matrix metalloproteases (MMP) are other mechanisms that decrease the availability or biological activity of inflammatory chemokines to down-regulate immune responses. ${ }^{70,71}$

Although the chemokine network is an important component of tumor biology, little is known regarding tumor regulation of chemokine expression and function in the cancer microenvironment and/or the molecular mechanisms mediating this regulation. Studies in murine cancer models and analyses of tumor specimens of cancer patients have shown that tumors up-regulate the expression of chemokines, promoting their growth, and downregulate the expression of tumor-suppressing chemokines. ${ }^{12,13,20}$ Tumor cells secrete many soluble factors such as cytokines, proteases, and hormones, which can regulate the expression of chemokines and their receptors in the tumor microenvironment. Tumorinfiltrating leukocytes also produce many different chemokines and contribute to shaping the chemokine network within the tumor. Tumor-infiltrating M2 type macrophages and MDSCs produce CCL20 and CCL22, which in turn attract Tregs into the tumor. ${ }^{27,72}$ Tumorinfiltrating IFN-g producing T cells stimulate intra-tumor production of IFN-g-inducible CXCR3 ligands CXCL9 and CXCL10, recruiting more tumor-specific CTL and/ or NK cells that amplify the expression of these chemokines in tumors through IFN-g production. ${ }^{73}$ However, tumors can counteract this mechanism by ceasing the expression of anti-tumor chemokines. Recent studies in this laboratory have indicated that CXCL9 expression is down-regulated in tumor cells upon encountering T-cell-mediated immunity of the tumor host. A considerable proportion of tumor-cell clones derived from MCA-induced sarcomas and B16 melanomas growing in immunocompetent mice lost their ability to produce CXCL9 
in response to IFN-g stimulation. This deficiency in CXCL9 expression was irreversible and conferred a growth advantage of CXCL9-deficient tumor variants in immunocompetent hosts when compared to CXCL9-expressing tumor cells. ${ }^{74,75}$ These CXCL9-deficient tumor variants were rare in T cell-deficient RAG KO mice or in IFN-g KO mice when compared to wild-type hosts of tumors, suggesting that loss of CXCL9 expression in tumor cells occurs as a result of immuno-editing mediated through anti-tumor activity of T cells and IFN-g. ${ }^{75}$ Although the molecular mechanism of this loss is not yet known, preliminary results indicate that CXCL9 expression in tumor cells is inhibited at the transcriptional level. These findings indicate that tumor cells can down-regulate chemokine expression in response to immune stress mediated by effector molecules such as IFN-g.

While the molecular mechanisms regulating chemokine expression and function during tumor growth are not well understood, accumulating evidence from in vitro and in vivo studies in various cancer models indicate that this regulation occurs on transcriptional, posttranscriptional, and post-translational levels and is mediated via multiple mechanisms.

\section{A. Transcriptional Regulation of Chemokine Expression}

1. Oncoproteins and tumor-associated transcription factors-As a result of malignant transformation, tumor cells constitutively express many oncogenes that promote tumorigenesis by activating signaling pathways enhancing tumor cell proliferation or protection from apoptosis. Oncoproteins encoded by these oncogenes or products of their downstream signaling regulate the expression of genes involved in tumorigenesis at the transcriptional level through the direct binding to promoter of the target gene, which results in the activation or suppression of promoter activity. It is conceivable that oncogenes influence the expression of chemokines and/or their receptors in the tumor. Recent studies have demonstrated transcriptional regulation of several chemokines by oncoproteins. Constitutive activation and expression of the oncoprotein Ras up-regulates the expression of the key proangiogenic chemokines, CXCL1 and CXCL8, in cervical and thyroid cancer cells. ${ }^{76,77}$ In human breast adenocarcinoma cell lines, Ras modulated CXCL10/ CXCR3mediated signaling in favor of tumor growth. Whereas Ras up-regulated CXCL10, a potent anti-tumor chemokine, it also down-regulated the expression of the CXCR3B variant of CXCR3, which transduces signal-inhibiting tumor cell proliferation. Therefore, CXCL10 up-regulated in tumor cells by Ras most likely signals through another CXCR3 receptor variant, CXCR3A, which provokes the tumor cells to proliferate and migrate. ${ }^{78}$ Notably, the expression of another CXCR3 ligand, CXCL9, was not up-regulated by Ras, suggesting distinct regulatory pathways employed by tumors to modulate the expression of these two chemokines that exert similar anti-tumor functions.

Oncogene RET/PTC1 overexpressed in thyroid cancer cells mediates transcriptional activation of many pro-angiogenic CXC chemokines and the TAM chemoattractant CCL2. ${ }^{79}$ Malignant transformation of normal epithelial cells during breast cancer development results in nuclear translocation of b-catenin, which in turn activates transcription factor TCF-4. TCF-4 directly activates the promoter of CCL2 and up-regulates the expression of this protumor chemokine in invasive human breast cancer cell lines. ${ }^{80}$ 
Transcription factors, such as STAT-3 and NF-kB, are activated in cancer cells and promote tumorigenesis through multiple mechanisms including the induction and regulation of many proinflammatory cytokines and chemokines. Recent in vitro studies in murine melanoma, sarcoma, and colon carcinoma cell lines have indicated that STAT-3 suppresses mRNA expression and protein production of potent anti-tumor chemokines CXCL10 and CCL5 in these cells. ${ }^{81}$ Constitutive activation of NF-kB mediates the transcriptional up-regulation of pro-angiogenic chemokines CXCL1 and CXCL8. ${ }^{82}$

In summary, oncogenes and transcription factors activated during carcinogenesis directly enhance the expression of many $\mathrm{CXC}$ and $\mathrm{CC}$ chemokines that promote tumor angiogenesis and/or recruit leukocyte populations (e.g., MDSC, M2 macrophages), facilitating invasive tumor growth.

2. Tumor-Associated Hormones and Lipids-Tumor-secreted hormones estrogen and androgen, which mediate autocrine stimulation of breast or prostate cancer cells, can directly influence the expression of the potent pro-tumor chemokine CXCL12 and its receptor, CXCR4. Estrogen binding to CXCL12 and CXCR4 gene promoters up-regulates mRNA transcription and protein production of CXCL12 and CXCR $4 .{ }^{83}$ In prostate cancer cells, androgen hormone induces the expression of the transcription factor ERG, which upregulates the expression of CXCR4, facilitating pro-tumor activities of the CXCL12/CXCR4 axis. $^{84}$

Prostaglandin $\mathrm{E}_{2}\left(\mathrm{PGE}_{2}\right)$ is known as a regulator of many immune components during inflammation and cancer, including cytokine production and innate and adaptive immune cell activation, differentiation, and function. ${ }^{85} \mathrm{PGE}_{2}$ is overproduced in tumors by both tumor cells and tumor-infiltrating MDSC. Recent in vitro studies demonstrated $\mathrm{PGE}_{2}$ mediated transcriptional down-regulation of several chemokines involved in anti-tumor immunity: CCL5, CCL19 and CXCR3 ligands, CXCL9, CXCL10, and CXCL11. ${ }^{86}$ The molecular mechanism of this down-regulation has not been completely elucidated. It has been shown that cyclic adenosine monophosphate/ protein kinase A (c-AMP/PKA) pathway is required for $\mathrm{PGE}_{2}$-mediated down-regulation of chemokine expression, as treatment of cells with inhibitors of c-AMP/PKA signaling restored the expression of these chemokines. ${ }^{87} \mathrm{PGE}_{2}$ down-regulates the expression of CCL5 and CXCR3 ligands in different types of $\mathrm{DC}$ and, therefore, chemoattraction of tumor-specific T cells and NK cells to the sites of their activation by tumor antigen-presenting DCs might be inhibited in tumor hosts through this mechanism.

3. DNA Methylation-It is well known that malignant cells silence the expression of many tumor-suppressing genes through DNA methylation of the target gene promoter. Methylation of adenine or cytosine nucleotides within specific clusters (CpG islands) located in the gene promoter region results in chromatin remodeling and in subsequent transcriptional silencing of the promoter. It remains largely unknown whether tumor cells utilize this mechanism to regulate the expression of chemokines. In recent studies, Song and colleagues $^{88}$ demonstrated such a mechanism of transcriptional down-regulation of CXCL14 chemokine in human prostate cancer cells. CXCL14 is constitutively expressed in many normal tissues, but its expression is down-regulated in prostate cancer. ${ }^{50}$ This chemokine 
might inhibit tumor growth through the inhibition of angiogenesis and/or through recruiting DC and NK cells into the tumor. ${ }^{49}$ Hypermethylated CpG islands have been detected within the promoter region of CXCL14 gene in human prostate cancer cell lines deficient in the expression of this chemokine. Treatment of tumor cells with the demethylating drug 5-aza-2deoxycytidine (decitabine or DAC) restored CXCL14 mRNA and protein expression. ${ }^{88}$ To our knowledge, this is the first evidence of chemokine down-regulation in tumors by DNA methylation of the chemokine gene promoter. Results of our recent studies have indicated that the loss of another potent anti-tumor chemokine, CXCL9 expression, in murine MCA205 sarcoma and B16 melanoma cells contributes to accelerated growth of tumor variants deficient in this chemokine. ${ }^{75}$ Subsequent studies investigating the molecular mechanism of CXCL9 deficiency in these cancer cell lines have indicated that CXCL9 expression is also regulated through DNA methylation (Gorbachev A., manuscript in preparation). Similar to the results observed in studies of CXCL14 down-regulation in prostate cancer cells, ${ }^{88}$ treatment of CXCL9-deficient MCA205 or B16 tumor variants with the demethylating drug DAC restored mRNA expression and protein production of CXCL9 by tumor cells (Fig. 1). These studies reveal a previously unknown mechanism of action of the chemotherapeutic drug that, in addition to its direct cytotoxic effects on tumor cells, can restore intra-tumor production of potent anti-tumor chemokines. While investigating this mechanism, we did not detect hypermethylated DNA within the CXCL9 promoter by methylation-specific PCR and bisulfite sequencing of DNA extracted from CXCL9-deficient tumor variants. These results suggest that CXCL9 expression in tumor cells is regulated indirectly through methylation of other genes involved in the induction of this chemokine expression. This is entirely possible considering that the activation of IFN-inducible genes involves many different transcription factors activated downstream of IFN/ STAT-1 signaling. A recent report has indicated that the expression of chemokines CCL5, CCL20, CCL21, and CXCL10 in murine melanoma is indirectly inhibited through methylating the promoter of IRF-8, a member of interferon-inducible regulatory factor (IRF) family involved in IFN/STAT-1-mediated activation of IFN-inducible genes. ${ }^{89}$ Our previous studies have clearly indicated that IFN-g signaling through IFN-gR/STAT-1 is not impaired in CXCL9deficient tumor variants, as they are still able to express another IFN-g-inducible chemokine, CXCL10, and to up-regulate class I MHC molecules in response to IFN-g stimulation. ${ }^{74,75}$ Although IFN-g-induced transcriptional activation of both CXCL9 and CXCL10 genes requires initial signals through STAT-1 and NF-kB, there are differences in the downstream mechanisms activating promoters of these two genes. While the CXCL9 promoter is activated through binding of STAT- 1 to gRE site, the expression of the CXCL10 gene is activated through STAT-1 binding to the ISRE (interferon-stimulated response element) site. 90-92 Another recent study has indicated that the chemotherapeutic drug sulindac inhibits the transcriptional activation of CXCL9 in a murine macrophage cell line while IFN-g/STAT- 1mediated expression of CXCL10 remains intact. ${ }^{93}$ Therefore, it is likely that the expressions of these two chemokines in tumor cells are regulated by different molecular mechanisms.

\section{B. Post-Transcriptional Regulation of Chemokine Expression}

Chemokine expression during immune responses is often regulated through modulating chemokine mRNA stability, which subsequently increases or decreases mRNA translation and accumulation of chemokine protein. However, little is known about this mechanism 
regulating chemokine expression in tumors. Studies of colon cancer cell lines have indicated that the RNA-binding protein HuR, which is often up-regulated in tumors, stabilizes mRNA of several tumor-promoting factors, including COX-2, VEGF, and the pro-angiogenic chemokine CXCL8, through binding to ARE regulatory sites located in their mRNA transcripts. This stabilization markedly increases the half-life of CXCL8 mRNA and can lead to overexpression of this angiogenesis-promoting chemokine in colon cancer. ${ }^{94}$ Another study reported stabilization of CXCL10 mRNA in human lymphoma cell lines mediated through the p38/SAPK2 kinase pathway activated by oncoprotein LMP-1, which is constitutively expressed in these cell lines. ${ }^{95}$ As these studies were performed in vitro, it is not clear whether tumors employ this mechanism of chemokine regulation during in vivo growth. More intensive studies are required to test this potential mechanism of chemokine expression regulation in the tumor microenvironment.

\section{Post-translational Regulation of Chemokine Availability and Functions in the Tumor}

Tumors can regulate the availability of chemokines and/or their functions in the tumor microenvironment through several mechanisms. First, tumor cells express many chemokine receptors and might use them not only to respond to stimulatory signals provided by protumor chemokines but also to absorb chemokines that recruit effector immune cells (e.g., CTL and NK cells), depriving these cells from chemokine signals required for them to enter the tumor. Such competition for chemokines between tumor cells and CTL is suggested by the observation of abundant CXCR3 expression by tumor cells in some aggressive cancers such as breast adenocarcinoma and melanoma. ${ }^{96,97}$ However, more studies are required to prove that this mechanism has a significant negative impact on CTL recruitment into the tumor.

A second mechanism is a chemical modification of chemokines that alters their function within the tumor. The best example is a modification of CCL2 by reactive nitrogen species (RNS) that was recently demonstrated in several different human and murine cancers. RNS, which are abundantly produced by many tumors, induce nitrosylation of CCL2 molecule. This RNS-modified CCL2 variant does not attract tumor-reactive CTL, but it still recruits regulatory M2 macrophages in the tumor. ${ }^{58}$ Blockade of RNS production by chemotherapeutic drugs restores the ability of CCL2 to recruit adoptively transferred T cells into tumors and induces T-cell-mediated tumor rejection.

A third mechanism is post-translational degradation or cleavage of chemokines by tumorsecreted proteases. Serine protease CD26 cleaves many chemokines, either increasing or decreasing their biological activity. ${ }^{98}$ Cleavage of CXCR3 ligands CXCL9, CXCL10, and CXCL11 by CD26 has been shown to reduce their chemotactic functions while preserving their angiostatic bioactivity. ${ }^{99}$ A recent study demonstrated that CD26 synergizes with another protease, CD13, to truncate CXCL11, reducing its chemoattracting functions. ${ }^{100}$ Therefore, CD26 potentially may reduce anti-tumor functions of CXCR3 chemokines by inhibiting their ability to recruit CTL into the tumor. On the other hand, this protease is able to negatively regulate functions of certain pro-tumor chemokines. In human neuroblastoma, CD26 degrades pro-angiogenic chemokine CXCL12 and its receptor, CXCR4, and 
overexpression of CD26 protease in human neuroblastoma cells resulted in the inhibition of tumor growth in nude mice. ${ }^{101}$

Matrix metalloproteases (MMP) are produced in tumors and promote tumor invasion into surrounding tissues by digesting the extracellular matrix. MMP-8 and MMP-9 proteases impose differential effects on CXCR3 ligands: MMP-8 degrades CXCL9 and cleaves CXCL10, while MMP-9 cleaves CXCL9 and degrades CXCL10. ${ }^{102}$ In vitro studies have demonstrated that MMP-mediated structural modifications reduce the chemotactic functions of another CXCR3 ligand, CXCL11. ${ }^{103}$ However, it remains unclear whether tumors regulate the functions of CXCR3 ligands in vivo through MMP-8- and MMP-9-mediated degradation.

Overall, tumors can mediate regulation of chemokine expression and/or function through different regulatory mechanisms. These mechanisms include transcriptional inhibition or activation of chemokine or chemokine receptor genes by oncoproteins, by tumor-secreted hormones or lipids, and by DNA methylation. Post-transcriptional modulation of chemokine mRNA stability, and, post-translational regulation of chemokine function through chemical modifications of chemokine protein. In Figure 2, these currently known regulatory mechanisms are summarized and the affected chemokines are depicted, with a brief description of the way in which this regulation benefits tumor growth. More studies are required to completely elicidate the molecular mechanisms employed by cancer cells to regulate chemokine expression. These studies will define new therapeutic targets and novel approaches to suppress or to enhance chemokine expression in tumors as desired.

\section{MANIPULATING THE CHEMOKINE EXPRESSION IN CANCER THERAPY}

Chemokines and their signals significantly influence tumor growth, and the modulation of chemokine expression and/or signaling in the tumor microenvironment is an attractive and rapidly developing approach in cancer therapy. Currently, three basic approaches of manipulating chemokine network are being tested in preclinical studies or in clinical trials. The first approach is based on the blockade of chemokine signals that promote tumor growth and dissemination. This blockade is achieved either by neutralizing pro-tumor chemokines or by blocking receptors via specific antibodies, peptides, or shorthairpin RNAs (shRNAs). Therapeutic targets currently being tested include angiogenic chemokines CXCL8 and CXCL12 or their receptors CXCR1 or CXCR4. Preclinical studies in a human tumor xenograft model have indicated that blocking the expression of CXCL8 by shRNAs specifically targeting CXCL8 mRNA results in tumor regression. ${ }^{104}$ Neutralizing CXCL12 or blocking its receptor CXCR4 by antibodies inhibits the development of metastasis in a murine xenograft model of glioblastoma. ${ }^{105}$ Targeting CCL2, the potent chemoattractant of immunoregulatory cells, is currently being evaluated in prostate and ovarian cancer patients. 106

A second approach is based on the delivery of potent anti-tumor chemokines using chemokine gene-encoding plasmids or viral vectors to induce constitutive expression of the desired chemokine, either in the tumor or in the selected population of tumor-infiltrating 
immune cells. Promising results have been achieved in preclinical studies using overexpression of chemokine CCL21 either in tumor cells or in DCs. Because CCL21 is critical for the recruitment of tumor-antigen-presenting DCs into tumor-draining lymph nodes to prime and activate tumor-reactive T cells, one therapeutic approach uses DCs transduced with a viral vector to constitutively express CCL21. Studies in murine models of melanoma and lung cancer have indicated that CCL21-expressing tumor-antigen-presenting DCs may be effective as a vaccine activating anti-tumor immune responses capable of tumor growth inhibition or tumor eradication. ${ }^{107,108}$ Currently, this therapeutic approach is being tested in clinical trials in melanoma and lung cancer patients. As CCL21 also contributes to the formation of TLS in the tumor and, therefore, might promote activation of tumor-reactive $\mathrm{T}$ and $\mathrm{B}$ cells in the tumor microenvironment, intra-tumor delivery of this chemokine using nanoparticles is being tested. ${ }^{109}$ However, this approach might have undesired side effects, as CCL21 is also known as a chemoattractant of MDSC or Tregs into the tumor or TLS. 27,55

Another group of chemokines that can potentially be used to optimize anti-tumor immune responses are the CXCR3 ligands CXCL9, CXCL10, and CXCL11. In addition to their angiostatic effects these chemokines are potent chemoattractants of CXCR3-expressing CTL and NK cells critical for immune-mediated eradication of tumor. ${ }^{39-42}$ Insufficient recruitment of these effector cells into the tumor is a frequent problem limiting many immunotherapeutic approaches such as adoptive transfer of conditioned tumor-reactive $\mathrm{T}$ cells into cancer patients. Over-expression of CXCR3 chemokines in the tumor might overcome these therapeutic limitations by enhancing the intratumor recruitment of CXCR3expressing tumor-reactive T cells. This concept was tested in several murine models of cancer by delivery of CXCL9- or CXCL10-expressing viral vectors into tumor cells. Overexpression of CXCL10 in a murine hemangioma ${ }^{110}$ or CXCL9 in murine fibrosarcoma and breast carcinoma ${ }^{74,111}$ resulted in inhibition of tumor growth, and complete rejection of tumors was observed in a considerable number of tumor hosts. These therapeutic effects were mediated by T-cell immunity and were associated with robust intra-tumor recruitment of T cells. More recent studies demonstrated T-cell-mediated therapeutic effects of CXCL9 delivered into established murine melanomas by CXCL9-encoding plasmids. ${ }^{59}$ Therefore, intra-tumor delivery of CXCR3 ligands, particularly CXCL9, seems a potent immunotherapeutic approach to enhance recruitment of effector tumor-reactive T cells into tumors. This approach, however, has certain limitations, as overexpression of CXCR3binding chemokines did not result in complete eradication of tumors and these tumors were able to outgrow in some hosts. Mechanisms limiting therapeutic effects of enforced CXCR3binding chemokine expression in tumors are not known as yet. Another potential pitfall that must be considered during the design of this therapeutic approach is that tumor cells in some murine and human cancers express CXCR3 and might use CXCR3 signals to migrate and form metastases in distant sites expressing CXCR3 ligands. ${ }^{112,113}$

Another interesting strategy to bypass the deficiency of CTL-attracting chemokines in the tumor has been recently proposed. This approach utilizes tumor-specific CTLs that are genetically engineered to co-express receptors to tumor-specific antigens and to chemokines that are abundantly expressed in the tumor. Recent preclinical studies have indicated the eradication of human neuroblastoma and mesothelioma xenografts in immunodeficient mice adoptively transferred with tumor-specific CTL transduced to constitutively express CCR2, 
as CCL2 chemokine is abundant in these tumors. ${ }^{114,115}$ The results of these studies suggest that the migration of CTL into tumors can be enhanced by transducing these effector cells with the receptors to chemokines overproduced by cancer cells.

A third approach of chemokine-based therapy is targeting molecular mechanisms that tumors use to regulate chemokine expression and/or functions. Recent studies defined posttranslational modification of chemokines as one such mechanism. Many tumors secrete reactive nitrogen species (RNS) that chemically modify the structure of CCL2, rendering this chemokine to recruit immunoregulatory myeloid cells into tumor instead of recruiting CTL. ${ }^{58}$ Blockade of RNS production by certain chemotherapeutic drugs can reverse this chemical conversion of CCL2 and restores CCL2-mediated recruitment of CTL into the tumor. ${ }^{58}$ Another potential therapeutic target includes immunoregulatory cytokines (IL-10) or prostaglandin $\mathrm{E}_{2}\left(\mathrm{PGE}_{2}\right)$ that suppress intratumor production of CXCR3 ligands or hypoxia-inducible factors that up-regulate the expression of the Treg chemoattractant CCL28. 54

\section{CONCLUSION}

Recent preclinical studies in murine models have indicated that potent tumor-suppressing effects can be achieved through modulating the chemokine expression in tumors via certain chemotherapeutic drugs or chemokine-expressing viral vectors. The inhibition of chemokines promoting angiogenesis, tumor invasion, or recruitment of regulatory cells and/or the expression of chemokines promoting activation and recruitment of tumor-reactive effector cells is likely to amplify the therapeutic effects of adoptive cell transfer, DC vaccination, or blockade of immune checkpoints; these approaches that are currently being evaluated in cancer clinical trials. As molecular mechanisms employed by tumors to modulate chemokine expression are very complex, more rigorous studies are required to completely define these mechanisms. These studies will identify molecular targets to modulate the expression of chemokines in the tumor microenvironment, which will advance immune-mediated destruction of cancer.

\section{ACKNOWLEDGMENTS}

Studies of Gorbachev AV contributed to this review were supported by the grant IRG-91-022-12 from the American Cancer Society and by the grant 10SDG2630107 from the American Heart Association.

\section{ABBREVIATIONS}

$\begin{array}{ll}\text { CTL } & \text { cytolytic T cells } \\ \text { DC } & \text { dendritic cells } \\ \text { MDSC } & \text { myeloid-derived suppressor cells } \\ \text { TLS } & \text { tertiary lymphoid structures } \\ \text { Tregs } & \text { T regulatory cells }\end{array}$




\section{REFERENCES}

1. Zlotnik A, Yoshie O. Chemokines: a new classification system and their role in immunity. Immunity. 2000;12:121-7. [PubMed: 10714678]

2. Rot A, von Andrian UH. Chemokines in innate and adaptive immune defense: basic chemokine grammar for immune cells. Ann Rev Immunol. 2004;22:891-928. [PubMed: 15032599]

3. Mantovani A Chemokines: Introduction and overview. Chem Immunol. 1999;72:1. [PubMed: 10550926]

4. Lukacs NW, Hogaboam C, Campbell E, Kunkel SL. Chemokines: function, regulation and alteration of inflammatory responses. Chem Immunol. 1999;72:102. [PubMed: 10550933]

5. Zlotnik A, Yoshie O. The chemokine superfamily revisited. Immunity. 2012;36:705-16. [PubMed: 22633458]

6. Broxmeyer HE. Chemokines in hematopoesis. Curr Opin Hematol. 2008;15:49-58. [PubMed: 18043246]

7. Mantovani A, Allavena P, Sica A, Balkwill F. Cancerrelated inflammation. Nature. 2008;454:43644. [PubMed: 18650914]

8. Kaiser A, Donnadieu E, Abastado JP, Trautmann A, Nardin A. CC chemokine ligand 19 secreted by mature dendritic cells increases naive $T$ cell scanning behavior and their response to rare cognate antigen. J Immunol. 2005;175:2349-56. [PubMed: 16081805]

9. Molon B, Gri G, Bettella M, Gomez-Mouton C, Lanzavecchia A, Martinez AC, Manes S, Viola A. T cell costimulation by chemokine receptors. Nat Immunol. 2005;6:465-71. [PubMed: 15821738]

10. Rosenblum JM, Shimoda N, Schenk AD, Zhang H, Kish DD, Keslar K, Farber JM, Fairchild RL. CXC chemokine ligand (CXCL) 9 and CXCL10 are antagonistic costimulation molecules during the priming of alloreactive T cell effectors. J Immunol. 2010;184:3450-60. [PubMed: 20194716]

11. Mantovani A The chemokine system: redundancy for robust outputs. Immunol Today. 1999;20:254-7. [PubMed: 10354549]

12. Viola A, Sarukhan A, Bronte V, Molon B. The pros and cons of chemokines in tumor immunology. Trends Immunol. 2012;33:496-504. [PubMed: 22726608]

13. Franciszkiewicz K, Boissonas A, Boutet M, Combadiere C, Mami-Chouaib F. Role of chemokines and chemokine receptors in shaping the effector phase of the antitumor immune response. Cancer Res. 2012;72:6325-32. [PubMed: 23222302]

14. Struyf S, Salogni L, Burdick MD, Vandercappellen J, Gouwy M, Noppen S, Proost P, Opdenakker G, Parmentier M, Gerard C, Sozanni S, Strieter RM, Van Damme J. Angiostatic and chemotactic activities of the CXC chemokine CXCL4L1 are mediated by CXCR3. Blood. 2011;117:480-8. [PubMed: 20980681]

15. Luster AD, Greenberg SM, Leder P. The IP-10 chemokine binds to a specific cell surface heparan sulfate site shared with platelet factor 4 and inhibits endothelial cell proliferation. J Exp Med. 1995;182:219-31. [PubMed: 7790818]

16. Xanthou G, Williams TJ, Pease JE. Molecular characterization of the chemokine receptor CXCR3: evidence for the involvement of distinct extracellular domains in a multi-step model of ligand binding and receptor activation. Eur J immunol. 2003;33:2927-36. [PubMed: 14515277]

17. Strieter RM. Chemokines: not just leukocyte chemoattractants in the promotion of cancer. Nat Immunol. 2001;2:285-6. [PubMed: 11276195]

18. Billottet C, Quemener C, Bikfalvi A. CXCR3, a doubleedged sword in tumor progression and angiogenesis. Biochimica et Biophysica Acta. 2013;1836:287-95. [PubMed: 23994549]

19. Balkwill F, Charles KA, Mantovani A. Smoldering and polarized inflammation in the initiation and promotion of malignant disease. Cancer Cell. 2005;7:211-17. [PubMed: 15766659]

20. Mantovani A, Savino B, Locati M, Zammataro L, Allavena P, Bonecchi R. The chemokine system in cancer biology and therapy. Cytokine \& Growth Factor Reviews. 2010;21:27-39. [PubMed: 20004131]

21. Ondondo B, Jones E, Godkin A, Gallimore A. Home sweet home: the tumor microenvironment as a haven for regulatory T cells. Front Immunol. 2013;4:197. [PubMed: 23874342] 
22. Tan MCB, Goedegebuure PS, Belt BA, Flaherty B, Sankpal N, Gillanders WE, Eberlein TJ, Hsieh CS, Linehan D. Disruption of CCR5-dependent homing of regulatory T cells inhibits tumor growth in a murine model of pancreatic cancer. J Immunol. 2009;182:1746-55. [PubMed: 19155524]

23. Sallusto F, Lanzavecchia A. Understanding dendritic cell and T-lymphocyte traffic through the analysis of chemokine receptor expression. Immunol Rev. 2000;177:134-40. [PubMed: 11138771]

24. Forster R, Schubel A, Breitfeld D, Kremmer E, Renner-Muller I, Wolf E, Lipp M. CCR7 coordinates the primary immune response by establishing functional microenvironments in secondary lymphoid organs. Cell 1999;99:23-33. [PubMed: 10520991]

25. Asperti-Boursin F, Real E, Bismuth G, Trautmann A, Donnadieu E. CCR7 ligands control basal T cell motility within lymph node slices in a phosphoinositide 3-kinaseindependent manner. J Exp Med. 2007;204:1167-79. [PubMed: 17485513]

26. Shields JD, Kourtis IC, Tomei AA, Roberts JM, Swartz MA. Induction of Lymphoidlike Stroma and Immune Escape by Tumors That Express the Chemokine CCL21. Science. 2010;328:749-52. [PubMed: 20339029]

27. Curiel TJ, Coukos G, Zou L, Alvarez X, Cheng P, Mottram P, Evdemon-Hogan M, Conejo-Garcia GR, Zhang L, Burow M, Zhu Y, Wei S, Kryczek I, Daniel B, Gordon A, Myers L, Lackner A, Disis ML, Knutson KL, Chen L, Zou W. Specific recruitment of regulatory T cells in ovarian carcinoma fosters immune privilege and predicts reduced survival. Nat Med. 2004;10:942-9. [PubMed: 15322536]

28. Gobert M, Treilleux I, Bendriss-Vermare N, Bachelot T, Goddard-Leon S, Arfi V, Biota C, Doffin AC, Durand I, Olive D, Perez S, Pasqual N, Faure C, Ray-Coquard I, Puisieux A, Caux C, Blay JY, Ménétrier-Caux C. Regulatory T cells recruited through CCL22/CCR4 are selectively activated in lymphoid infiltrates surrounding primary breast tumors and lead to an adverse clinical outcome. Cancer Res. 2009;69:2000-9. [PubMed: 19244125]

29. Olkhanud PB, Baatar D, Bodogai M, Hakim F, Gress R, Anderson RL, Deng J, Xu M, Briest S, Biragyn A. Breast cancer lung metastasis requires expression of chemokine receptor CCR4 and regulatory T cells. Cancer Res. 2009;69:5996-6004. [PubMed: 19567680]

30. Galvez BG, Matias-Roman S, Oblander SA, Tryggvason K, Apte SS, Arroyo AG. Membrane type 1-matrix metalloproteinase is regulated by chemokines monocytechemoattractant protein-1/ccl2 and interleukin-8/ CXCL8 in endothelial cells during angiogenesis. J Biol Chem. 2005;280:12928. [PubMed: 15516694]

31. Singh S, Singh AP, Sharma B, Owen LB, Singh RK. CXCL8 and its cognate receptors in melanoma progression and metastasis. Future Oncol. 2010;6:111-6. [PubMed: 20021212]

32. Sawanobori Y, Ueha S, Kurachi M, Shimaoka T, Talmadge JE, Abe J, Shono Y, Kitabatake M, Kakimi K, Mukaida N, Matsushima K. Chemokine-mediated rapid turnover of myeloid-derived suppressor cells in tumor-bearing mice. Blood. 2008;111:5457-66. [PubMed: 18375791]

33. Bellocq A, Antoine M, Flahault A, Philippe C, Crestani B, Bernaudin JF, Mayaud C, Milleron B, Baud L, Cadranel J. Neutrophil alveolitis in bronchioloalveolar carcinoma: induction by tumorderived interleukin-8 and relation to clinical outcome. Am J Pathol. 1998;152:83-92. [PubMed: 9422526]

34. Li A, Varney ML, Valasek J, Godfrey M, Dave BJ, Singh RK. Autocrine role of interleukin-8 in induction of endothelial cell proliferation, survival, migration and MMP-2 production and angiogenesis. Angiogenesis 2005;8:63-71. [PubMed: 16132619]

35. Kryczek I, Wei S, Keller E, Liu R, Zou W. Stroma-derived factor (SDF-1/CXCL12) and human tumor pathogenesis. Am J Physiol Cell Physiol. 2007;292:C987-95. [PubMed: 16943240]

36. Zlotnik A, Burkhardt AM, Homey B. Homeostatic chemokine receptors and organ-specific metastasis. Nat Rev Immunol. 2011;11:597-606. [PubMed: 21866172]

37. Strieter RM. Belperio JA, Phillips RJ, Keane MP. CXC chemokines in angiogenesis of cancer. Semin Cancer Biol. 2005;14:195-200.

38. Romagnani P, Annunziato F, Lasagni L, Lazzeri E, Beltrame C, Francalanci M, Uguccioni M, Galli G, Cosmi L, Maurenzig L, Baggiolini M, Maggi E, Romagnani S, Serio M. (2001) Cell cycledependent expression of CXC chemokine receptor 3 by endothelial cells mediates angiostatic activity. J Clin Invest. 2001;107:56-63. 
39. Tannenbaum CS, Tubbs R, Armstrong D, Finke JH, Bukowski RM, Hamilton TA. The CXC chemokines IP-10 and Mig are necessary for IL-12-mediated regression of the mouse RENCA tumor. J Immunol. 1998;161:927-32. [PubMed: 9670971]

40. Narvaiza I, Mazzolini G, Barajas M, Duarte M, Zaratiegui M, Qian C, Melero I, Prieto J. Intratumoral coinjection of two adenoviruses, one encoding the chemokine IFNgamma-inducible protein-10 and another encoding IL-12, results in marked antitumoral synergy. J Immunol. 2000;164:3112-22. [PubMed: 10706701]

41. Ruehlmann JM, Xiang R, Niethammer AG, Ba Y, Pertl U, Dolman CS, Gillies SD, Reisfeld RA. MIG (CXCL9) chemokine gene therapy combines with antibody-cytokine fusion protein to suppress growth and dissemination of murine colon carcinoma. Cancer Res. 2001;61:8498-503. [PubMed: 11731434]

42. Dorsey R, Kundu N, Yang Q, Tannenbaum CS, Sun H, Hamilton TA, Fulton AM. Immunotherapy with interleukin-10 depends on the CXC chemokines inducible protein-10 and monokine induced by IFNgamma. Cancer Res. 2002;62:2606-10. [PubMed: 11980656]

43. Kondo T, Ito F, Nakazawa H, Horita S, Osaka Y, Toma H. High expression of chemokine gene as a favorable prognostic factor in renal cell carcinoma. J Urol. 2004;171:2171-75. [PubMed: 15126779]

44. Kunz M, Toksoy A, Goebeler M, Engelhardt E, Bröcker E, Gillitzer R. Strong expression of the lymphoattractant C-X-C chemokine Mig is associated with heavy infiltration of T cells in human malignant melanoma. J Pathol. 1999;189:552-8. [PubMed: 10629557]

45. Dengel LT, Norrod AG, Gregory BL, Clancy-Thompson E, Burdick MD, Strieter RM, Slingluff CL, Mullins DW. Interferons induce CXCR3-cognate chemokine production by human metastatic melanoma. J Immunother. 2010;33:965-74. [PubMed: 20948440]

46. Harlin H, Meng Y, Peterson AC, Zha Y, Tretiakova M, Slingluff C, McKee M, Gajewski TF. Chemokine expression in melanoma metastases associated with CD8+ T cell recruitment. Cancer Res. 2009;69:3077-85. [PubMed: 19293190]

47. Ohtani H, Jin Z, Takegawa S, Nakayama T, Yoshie O. Abundant expression of CXCL9 by stromal cells that include dendritic cells and accumulation of CXCR3+ T cells in lymphocyterich gastric carcinoma. J Pathol. 2009;217:21-31. [PubMed: 18980207]

48. Frederick MJ, Henderson Y, Xu X, Deavers MT, Sahin AA, Wu H, Lewis DE, El-Naggar AK, Clayman GL. In vivo expression of the novel CXC chemokine BRAK in normal and cancerous human tissue. Am J Pathol. 2000;156:1937-50. [PubMed: 10854217]

49. Shellenberger TD, Wang M, Gujrati M, Jayakumar A, Strieter RM, Burdick MD, Ioannides CG, Efferson CL, El-Naggar AK, Roberts D, Clayman GL, Frederick MJ. BRAK/CXCL14 is a potent inhibitor of angiogenesis and a chemotactic factor for immature dendritic cells. Cancer Res. 2004:64:8262-70. [PubMed: 15548693]

50. Shurin GV, Ferris R, Tourkova IL, Perez L, Lokshin A, Balkir L, Collins B, Chatta GS, Shurin MR. Loss of new chemokine CXCL14 in tumor tissue is associated with low infiltration by dendritic cells (DC), while restoration of human CXCL14 expression in tumor cells causes attraction of DC both in vitro and in vivo. J Immunol. 2005;174:5490-8. [PubMed: 15843547]

51. Matsumura S, Wang B, Kawashima N, Braunstein S, Badura M, Cameron TO, Babb JS, Schneider RJ, Formenti SC, Dustin ML, Demaria S. Radiation-induced CXCL16 release by breast cancer cells attracts effector T cells. J Immunol. 2008;181:3099-107. [PubMed: 18713980]

52. Gutwein P, Schramme A, Sinke N, Abdel-Bakky MS, Voss B, Obermüller N, Doberstein K, Koziolek M, Fritzsche F, Johannsen M, Jung K, Schaider H, Altevogt P, Ludwig A, Pfeilschifter J, Kristiansen G. Tumoural CXCL16 expression is a novel prognostic marker of longer survival times in renal cell cancer patients. Eur J Cancer. 2009;45:478-89. [PubMed: 19070478]

53. Ohta M, Tanaka F, Yamaguchi H, Sadanaga N, Inoue H, Mori M. The high expression of Fractalkine results in a better prognosis for colorectal cancer patients. Int J Oncol. 2005;26:41-7. [PubMed: 15586223]

54. Facciabene A, Peng X, Hagemann IS, Balint K, Barchetti A, Wang LP, Gimotty PA, Gilks CB, Lal P, Zhang L, Coukos G. Tumour hypoxia promotes tolerance and angiogenesis via CCL28 and T(reg) cells. Nature. 2011;475:226-30. [PubMed: 21753853] 
55. Iellem A, Mariani M, Lang R, Recalde H, Panina-Bordignon P, Sinigaglia F, D’Ambrosio D. Unique chemotactic response profile and specific expression of chemokine receptors CCR4 and CCR8 by CD4(+) CD25(+) regulatory T cells. J Exp Med. 2001;194:847-853. [PubMed: 11560999]

56. Qian BZ, Li J, Zhang H, Kitamura T, Zhang J, Campion LR, Kaiser EA, Snyder LA, Pollard JW. CCL2 recruits inflammatory monocytes to facilitate breast-tumour metastasis.Nature.2011;475:222-5. [PubMed: 21654748]

57. Sawanobori Y, Ueha S, Kurachi M, Shimaoka T, Talmadge JE, Abe J, Shono Y, Kitabatake M, Kakimi K, Mukaida N, Matsushima K. Chemokine-mediated rapid turnover of myeloid-derived suppressor cells in tumor-bearing mice. Blood. 2008;111:5457-66. [PubMed: 18375791]

58. Molon B, Ugel S, Del Pozzo F, Soldani C, Zilio S, Avella D, De Palma A, Mauri P, Monegal A, Rescigno M, Savino B, Colombo P, Jonjic N, Pecanic S, Lazzarato L, Fruttero R, Gasco A, Bronte $\mathrm{V}$, Viola A. Chemokine nitration prevents intratumoral infiltration of antigen-specific T cells. J Exp Med. 2011;208:1949-62. [PubMed: 21930770]

59. Hong M, Puaux AL, Huang C, Loumagne L, Tow C, Mackay C, Kato M, Prévost-Blondel A, Avril MF, Nardin A, Abastado JP. Chemotherapy induces intratumoral expression of chemokines in cutaneous melanoma, favoring T-cell infiltration and tumor control. Cancer Res. 2011;71:6997-09. [PubMed: 21948969]

60. Friedman RS, Jacobelli J, Krummel MF. Surface-bound chemokines capture and prime T cells for synapse formation. Nat Immunol. 2006;7:1101-8. [PubMed: 16964261]

61. Dieu-Nosjean MC, Antoine M, Danel C, Heudes D, Wislez M, Poulot V, Rabbe N, Laurans L, Tartour E, de Chaisemartin L, Lebecque S, Fridman WH, Cadranel J. Long-term survival for patients with non-small-cell lung cancer with intratumoral lymphoid structures. J Clin Oncol. 2008;26:4410-17. [PubMed: 18802153]

62. oronella JA, Spier C, Welch M, Trevor KT, Stopeck AT, Villar H, Hersh EM. Antigen-driven oligoclonal expansion of tumor-infiltrating B cells in infiltrating ductal carcinoma of the breast. J Immunol. 2002;169:1829-36. [PubMed: 12165506]

63. Das S, Sarrou E, Podgrabinska S, Cassella M, Mungamuri SK, Feirt N, Gordon R, Nagi CS, Wang Y, Entenberg D, Condeelis J, Skobe M. Tumor cell entry into the lymph node is controlled by CCL1 chemokine expressed by lymph node lymphatic sinuses. J Exp Med. 2013;210:1509-28. [PubMed: 23878309]

64. Creagh EM, O'Neill LA. TLRs, NLRs and RLRs: a trinity of pathogen sensors that co-operate in innate immunity. Trends Immunol. 2006;27:352-7. [PubMed: 16807108]

65. Mortier A, Van Damme J, Proost P. Overview of the mechanisms regulating chemokine activity and availability. Immunol Letters. 2012;145:2-9.

66. Biswas R, Datta S, Gupta JD, Novotny M, Tebo J, Hamilton TA. Regulation of chemokine mRNA stability by lipopolysaccharide and IL-10. J Immunol. 2003;170:6202-8. [PubMed: 12794151]

67. Hamilton TA, Ohmori Y, Tebo J. Regulation of chemokine expression by antiinflammatory cytokines. Immunol Res. 2002;25:229-45. [PubMed: 12018462]

68. Sun D, Novotny M, Bulek K, Liu C, Li X, Hamilton T. Treatment with IL-17 prolongs the half-life of chemokine CXCL1 mRNA via the adaptor TRAF5 and the splicing-regulatory factor SF2 (ASF). Nat Immunol. 2011;12:853-60. [PubMed: 21822258]

69. Datta S, Novotny M, Li X, Tebo J, Hamilton TA. Toll IL-1 receptors differ in their ability to promote the stabilization of adenosine and uridine-rich elements containing mRNA. J Immunol. 2004;173:2755-61. [PubMed: 15294994]

70. Proost P, Schutyser E, Menten P, Struyf S, Wuyts A, Opdenakker G, Detheux M, Parmentier M, Durinx C, Lambeir AM, Neyts J, Liekens S, Maudgal PC, Billiau A, Van Damme J. Aminoterminal truncation of CXCR3 agonists impairs receptor signaling and lymphocyte chemotaxis, while preserving antiangiogenic properties. Blood. 2001;98:3554-61. [PubMed: 11739156]

71. Proost P, Mortier A, Loos T, Vandercappellen J, Gouwy M, Ronsse I, Schutyser E, Put W, Parmentier M, Struyf S, Van Damme J. Proteolytic processing of CXCL11 by CD13/ aminopeptidase $\mathrm{N}$ impairs CXCR3 and CXCR7 binding and signaling and reduces lymphocyte and endothelial cell migration. Blood. 2007;110:37-44. [PubMed: 17363734] 
72. Mailloux AW, Clark AM, Young MR. NK depletion results in increased CCL22 secretion and Treg levels in Lewis lung carcinoma via the accumulation of CCL22-secreting CD11b+CD11c+ cells. Int J Cancer. 2010;127:2598-611. [PubMed: 20198623]

73. Strieter RM, Burdick MD, Mestas J, Gomperts B, Keane MP, Belperio JA. Cancer CXC chemokine networks and tumor angiogenesis. Eur J Cancer. 2006;42:768-78. [PubMed: 16510280]

74. Gorbachev AV, Kobayashi H, Kudo D, Tannenbaum CS, Finke JH, Shu S, Farber JM, Fairchild RL. CXC chemokine ligand 9/monokine induced by IFNgamma production by tumor cells is critical for T cellmediated suppression of cutaneous tumors. J Immunol. 2007;15:2278-86.

75. Petro M, Kish D, Guryanova OA, Ilyinskaya G, Kondratova A, Fairchild RL, Gorbachev AV. Cutaneous tumors cease CXCL9/Mig production as a result of IFN- $\gamma$-mediated immunoediting. J Immunol. 2013;190:832-41. [PubMed: 23241877]

76. Melillo RM, Castellone MD, Guarino V, De Falco V, Cirafici AM, Salvatore G, Caiazzo F, Basolo F, Giannini R, Kruhoffer M, Orntoft T, Fusco A, Santoro M. The RET/PTC-RAS-BRAF linear signaling cascade mediates the motile and mitogenic phenotype of thyroid cancer cells. J Clin Invest. 2005;115:1068-81. [PubMed: 15761501]

77. Sparmann A, Bar-Sagi D. Ras-induced interleukin-8 expression plays a critical role in tumor growth and angiogenesis. Cancer Cell. 2004;6:447-58. [PubMed: 15542429]

78. Datta D, Flaxenburg JA, Laxmanan S, Geehan C, Grimm M, Waaga-Gasser AM, Briscoe DM, Pal $\mathrm{S}$. Ras-induced modulation of CXCL10 and its receptor splice variant CXCR3-B in MDA-MB-435 and MCF- 7 cells: relevance for the development of human breast cancer. Cancer Res. 2006;166:9509-18.

79. Borrello MG, Alberti L, Fischer A, Degl'innocenti D, Ferrario C, Gariboldi M, Marchesi F, Allavena P, Greco A, Collini P, Pilotti S, Cassinelli G, Bressan P, Fugazzola L, Mantovani A, Pierotti MA. Induction of a proinflammatory program in normal human thyrocytes by the RET/ PTC1 oncogene. Proc Natl Acad Sci USA. 2005;102:14825-30. [PubMed: 16203990]

80. Mestdagt M, Polette M, Buttice G, Noël A, Ueda A, Foidart JM, Gilles C. Transactivation of MCP-1/CCL2 by beta-catenin/TCF-4 in human breast cancer cells. Int J Cancer. 2006;118:35-42. [PubMed: 16003740]

81. Wang T, Niu G, Kortylewski M, Burdelya L, Shain K, Zhang S, Bhattacharya R, Gabrilovich D, Heller R, Coppola D, Dalton W, Jove R, Pardoll D, Yu H. Regulation of the innate and adaptive immune responses by Stat-3 signaling in tumor cells. Nat Med. 2004;10:48-54. [PubMed: 14702634]

82. Yang J, Richmond A. Constitutive IkappaB kinase activity correlates with nuclear factor-kappaB activation in human melanoma cells. Cancer Res. 2001;61:4901-9. [PubMed: 11406569]

83. Boudot A, Kerdivel G, Habauzit D, Eeckhoute J, Le Dily F, Flouriot G, Samson M, Pakdel F. Differential estrogenregulation of CXCL12 chemokine receptors, CXCR4 and CXCR7, contributes to the growth effect of estrogens in breast cancer cells. PLoS One. 2011;6:e20898. [PubMed: 21695171]

84. Chinni S, Singareddy R, Semaan L, Conley-Lacomb MK, St John J, Powell K, Iyer M, Smith D, Heilbrun LK, Shi D, Sakr W, Cher ML. Transcriptional regulation of CXCR4 in prostate tumor cells: significance of TMPRSS2-ERG fusions. Mol Cancer Res. 2013; published online;10.1158/1541-7786.MCR-12-0705.

85. Kalinski P Regulation of immune responses by prostaglandin E2. J Immunol. 2012;188:21-8. [PubMed: 22187483]

86. McIlroy A, Caron G, Blanchard S, Frémaux I, Duluc D, Delneste Y, Chevailler A, Jeannin P. Histamine and prostaglandin E up-regulate the production of Th2-attracting chemokines (CCL17 and CCL22) and downregulate IFN-gamma-induced CXCL10 production by immature human dendritic cells. Immunology. 2006;117:507-16. [PubMed: 16556265]

87. Qian X, Zhang J, Liu J. Tumor-secreted PGE2 inhibits CCL5 production in activated macrophages through cAMP/PKA signaling pathway. J Biol Chem. 2011;286:2111-20. [PubMed: 21097507]

88. Song EY, Shurin MR, Tourkova IL, Gutkin DW, Shurin GV. Epigenetic mechanisms of promigratory chemokine CXCL14 regulation in human prostate cancer cells. Cancer Res. 2010;70:4394-401. [PubMed: 20460540] 
89. Mattei F, Schiavoni G, Sestili P, Spadaro F, Fragale A, Sistigu A, Lucarini V, Spada M, Sanchez M, Scala S, Battistini A, Belardelli F, Gabriele L. IRF-8 controls melanoma progression by regulating the cross talk between cancer and immune cells within the tumor microenvironment. Neoplasia. 2012;14:1223-35. [PubMed: 23308054]

90. Ohmori Y, Hamilton TA. The interferon-stimulated response element and a kappa B site mediate synergistic induction of murine IP-10 gene transcription by IFNgamma and TNF-alpha. J Immunol. 1995;154:5235-44. [PubMed: 7730628]

91. Ohmori Y, Hamilton TA. STAT6 is required for the anti-inflammatory activity of interleukin-4 in mouse peritoneal macrophages. J Biol Chem. 1998;273:29202-9. [PubMed: 9786931]

92. Wong P, Severns CW, Guyer NB, Wright TM. A unique palindromic element mediates gamma interferon induction of mig gene expression. Mol Cell Biol. 1994;14:914-22. [PubMed: 8289831]

93. Sakaeda Y, Hiroi M, Shimojima T, Iguchi M, Kanegae H, Ohmori Y. Sulindac, a nonsteroidal antiinflammatory drug, selectively inhibits interferon-gamma-induced expression of the chemokine CXCL9 gene in mouse macrophages. Biochem Biophys Res Commun. 2006;350:339-44. [PubMed: 17010317]

94. Dixon DA, Tolley ND, King PH, Nabors LB, McIntyre TM, Zimmerman GA, Prescott SM. Altered expression of the mRNA stability factor HuR promotes cyclooxygenase-2 expression in colon cancer cells. J Clin Invest. 2001;108:1657-65. [PubMed: 11733561]

95. Vockerodt M, Pinkert D, Smola-Hess S, Michels A, Ransohoff RM, Tesch H, Kube D. The Epstein-Barr virus oncoprotein latent membrane protein 1 induces expression of the chemokine IP-10: importance of mRNA half-life regulation. Int J Cancer. 2005;114:598-605. [PubMed: 15578697]

96. Monteagudo C, Martin JM, Jorda E, Llombart-Bosch A. CXCR3 chemokine receptor immunoreactivity in primary cutaneous malignant melanoma: correlation with clinicopathological prognostic factors. J Clin Pathol. 2007;60:596-9. [PubMed: 16522748]

97. Mulligan AM, Raitman I, Feeley L, Pinnaduwage D, Nguyen LT, O’Malley FP, Ohashi PS, Andrulis IL. Tumoral lymphocytic infiltration and expression of the chemokine CXCL10 in breast cancers from the Ontario Familial Breast Cancer Registry. Clin Cancer Res. 2013;19:336-46. [PubMed: 23213058]

98. Van Damme J, Struyf S, Wuyts A, Van Coillie E, Menten P, Schols D, Sozzani S, De Meester I, Proost P. The role of CD26/DPP IV in chemokine processing. Chem Immunol. 1999;72:42-56. [PubMed: 10550929]

99. Proost P, Schutyser E, Menten P, Struyf S, Wuyts A, Opdenakker G, Detheux M, Parmentier M, Durinx C, Lambeir AM, Neyts J, Liekens S, Maudgal PC, Billiau A, Van Damme J. Aminoterminal truncation of CXCR3 agonists impairs receptor signaling and lymphocyte chemotaxis, while preserving antiangiogenic properties. Blood. 2001;98:3554-61. [PubMed: 11739156]

100. Proost P, Mortier A, Loos T, Vandercappellen J, Gouwy M, Ronsse I, Schutyser E, Put W, Parmentier M, Struyf S, Van Damme J. Proteolytic processing of CXCL11 by CD13/ aminopeptidase $\mathrm{N}$ impairs CXCR3 and CXCR7 binding and signaling and reduces lymphocyte and endothelial cell migration. Blood; 2007;110:37-44. [PubMed: 17363734]

101. Arscott WT, LaBauve AE, May V, Wesley UV. Suppression of neuroblastoma growth by dipeptidyl peptidase IV: relevance of chemokine regulation and caspase activation. Oncogene. 2009;28:479-91. [PubMed: 18978811]

102. Van den Steen PE, Husson SJ, Proost P, Van Damme J, Opdenakker G. Carboxyterminal cleavage of the chemokines MIG and IP-10 by gelatinase B and neutrophil collagenase. Biochem Biophys Res Commun. 2003;310:889-96. [PubMed: 14550288]

103. Cox JH, Dean RA, Roberts CR, Overall CM. Matrix metalloproteinase processing of CXCL11/ ITAC results in loss of chemoattractant activity and altered glycosaminoglycan binding. J Biol Chem. 2008;283:19389-99. [PubMed: 18411283]

104. Yoo JY, Kim JH, Kim J, Huang JH, Zhang SN, Kang YA, Kim H, Yun CO. Short hairpin RNAexpressing oncolytic adenovirus-mediated inhibition of IL-8: effects on antiangiogenesis and tumor growth inhibition. Gene Ther. 2008;15:635-51. [PubMed: 18273054] 
105. Kioi M, Vogel H, Schultz G, Hoffman RM, Harsh GR, Brown JM. Inhibition of vasculogenesis, but not angiogenesis, prevents the recurrence of glioblastoma after irradiation in mice. J Clin Invest. 2010;120:694-705. [PubMed: 20179352]

106. Garber K First results for agents targeting cancer-related inflammation. J Natl Cancer Inst. 2009;101:1110-2. [PubMed: 19671776]

107. Kirk CJ, Hartigan-O'Connor D, Mulé JJ. The dynamics of the T-cell antitumor response: chemokine-secreting dendritic cells can prime tumor-reactive T cells extranodally. Cancer Res. 2001;61:8794-802. [PubMed: 11751401]

108. Yang SC, Batra RK, Hillinger S, Reckamp KL, Strieter RM, Dubinett SM, Sharma S. Intrapulmonary administration of CCL21 gene-modified dendritic cells reduces tumor burden in spontaneous murine bronchoalveolar cell carcinoma. Cancer Res. 2006;66:3205-13. [PubMed: 16540672]

109. Kar UK, Srivastava MK, Andersson A, Baratelli F, Huang M, Kickhoefer VA, Dubinett SM, Rome LH, Sharma S. Novel CCL21-vault nanocapsule intratumoral delivery inhibits lung cancer growth. PLos One. 2011;6:e18758. [PubMed: 21559281]

110. Giese NA, Raykov Z, DeMartino L, Vecchi A, Sozzani S, Dinsart C, Cornelis JJ, Rommelaere J. Suppression of metastatic hemangiosarcoma by a parvovirus MVMp vector transducing the IP-10 chemokine into immunocompetent mice. Cancer Gene Ther. 2002;9:432-42. [PubMed: 11961666]

111. Walser TC, Ma X, Kundu N, Dorsey R, Goloubeva O, Fulton AM. Immune-mediated modulation of breast cancer growth and metastasis by the chemokine Mig (CXCL9) in a murine model. J Immunother. 2007;30:490-8. [PubMed: 17589289]

112. Ma X, Norsworthy K, Kundu N, Rodgers WH, Gimotty PA, Goloubeva O, Lipsky M, Li Y, Holt D, Fulton A. CXCR3 expression is associated with poor survival in breast cancer and promotes metastasis in a murine model. Mol Cancer Ther. 2009;8:490-8. [PubMed: 19276169]

113. Kawada K, Sonoshita M, Sakashita H, Takabayashi A, Yamaoka Y, Manabe T, Inaba K, Minato N, Oshima M, Taketo MM. Pivotal role of CXCR3 in melanoma cell metastasis to lymph nodes. Cancer Res. 2004;64:4010-7. [PubMed: 15173015]

114. Craddock JA, Lu A, Bear A, Pule M, Brenner MK, Rooney CM, Foster AE. Enhanced tumor trafficking of GD2 chimeric antigen receptor T cells by expression of the chemokine receptor CCR2b. J Immunother. 2010;33:780-8. [PubMed: 20842059]

115. Moon EK, Carpenito C, Sun J, Wang LC, Kapoor V, Predina J, Powell DJ Jr, Riley JL, June CH, Albelda SM. Expression of a functional CCR2 receptor enhances tumor localization and tumor eradication by retargeted human T cells expressing a mesothelin-specific chimeric antibody receptor. Clin Cancer Res. 2011;17:4719-30. [PubMed: 21610146] 

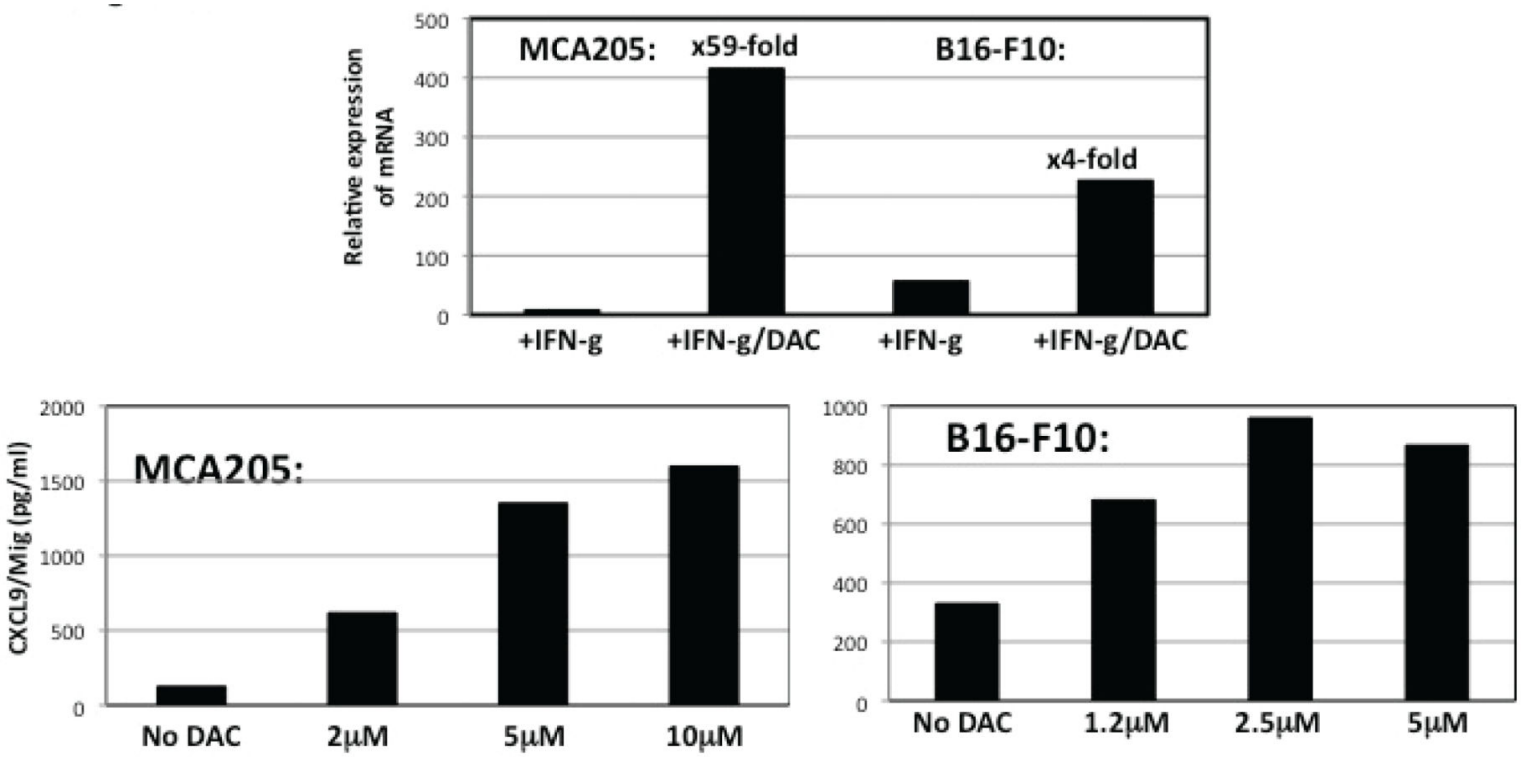

FIG. 1:

Treatment of CXCL9-deficient tumor cells with demethylating drug decitabine (DAC) restores IFN-g-inducible CXCL9 mRNA expression and protein production.

Upper panel: CXCL9-deficient variants of MCA205 fibrosarcoma or B16 melanoma were cultured with IFN-g alone or with IFN-g and DAC for $24 \mathrm{~h}$. Total cell RNA was extracted from cell cultures and the expression of CXCL9 mRNA was tested by quantitative RT-PCR. The expression level of mRNA isolated from tumor cells not stimulated with IFN-g was arbitrarily set at 1.0 and used to determine the relative expression levels in the IFN-gstimulated samples. Fold increase of CXCL9 mRNA levels in cells treated with DAC vs. non-treated cells is shown.

Lower panels: CXCL9-deficient variants of MCA205 fibrosarcoma or B16 melanoma were cultured with IFN-g alone or with IFN-g and different concentrations of DAC for $72 \mathrm{~h}$. Culture supernatants were collected and tested for CXCL9 protein by CXCL9-specific ELISA.. 


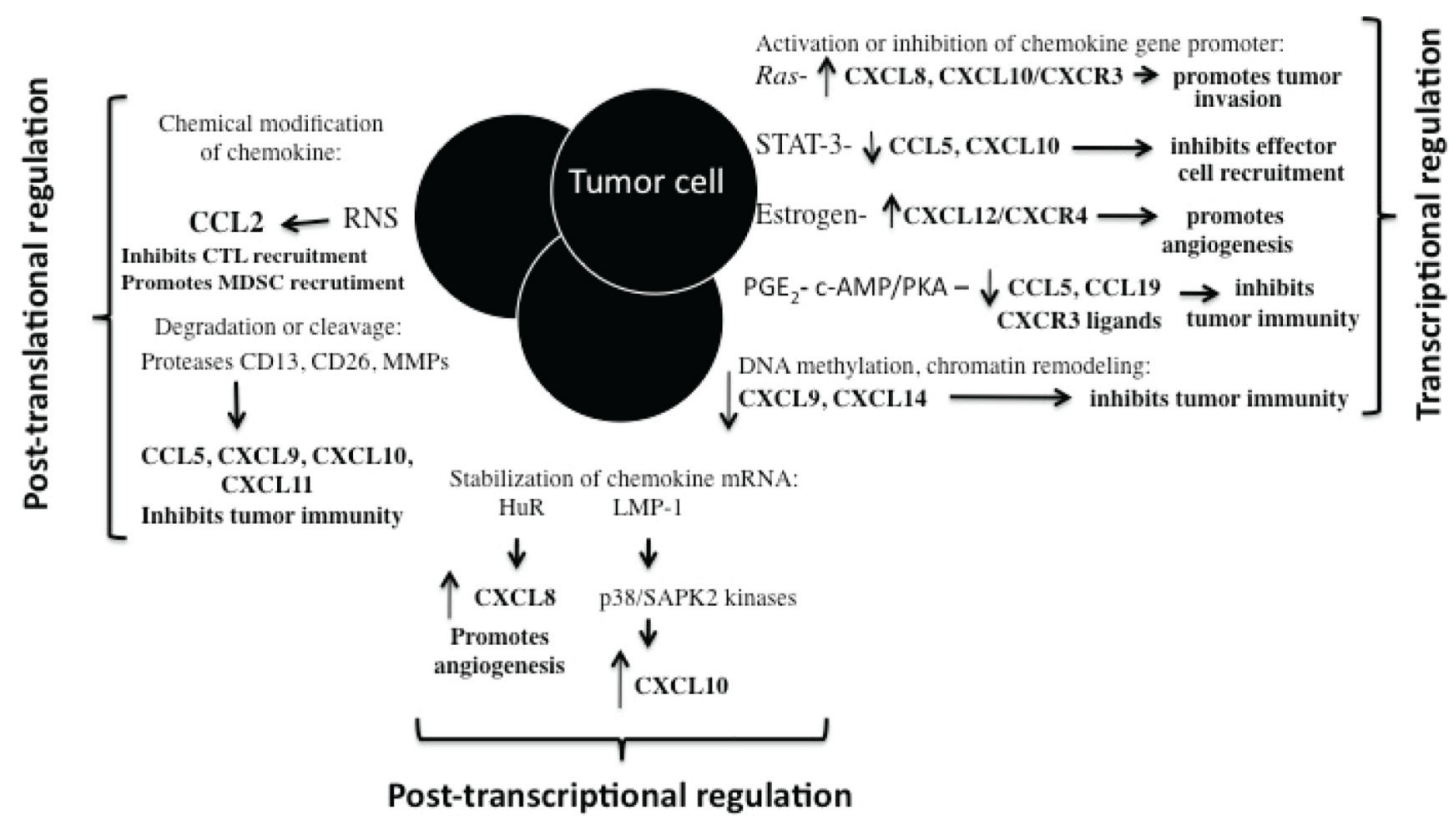

FIG. 2:

Mechanisms employed by tumor cells to regulate chemokine expression in the tumor microenvironment. Figure depicts currently known mechanisms used by tumors to regulate the expression of chemokines and their receptors. The examples of transcriptional regulation include (a) direct effects of oncoproteins (Ras), tumor-associated transcription factors (STAT-3), hormones (estrogen) or prostaglandin E2 (PGE2) on chemokine promoter that results in the activation $(\uparrow)$ or inhibition $(\downarrow)$ of chemokine expression and (b) inhibition of chemokine expression through DNA methylation. Post-transcriptional regulation is mediated through modulating stability of chemokine mRNA by transcription factors (HuR) or oncoproteins (LMP-1). Post-translational regulation of chemokine functions can be mediated by chemical modification of chemokine structure (nitrosylation by reactive nitrogen species (RNS) produced by tumor cells) or by cleavage of chemokine by serine proteases (CD13, CD26). Availability of chemokine may be decreased through degradation of chemokine protein by proteases produced in the tumor microenvironment. 


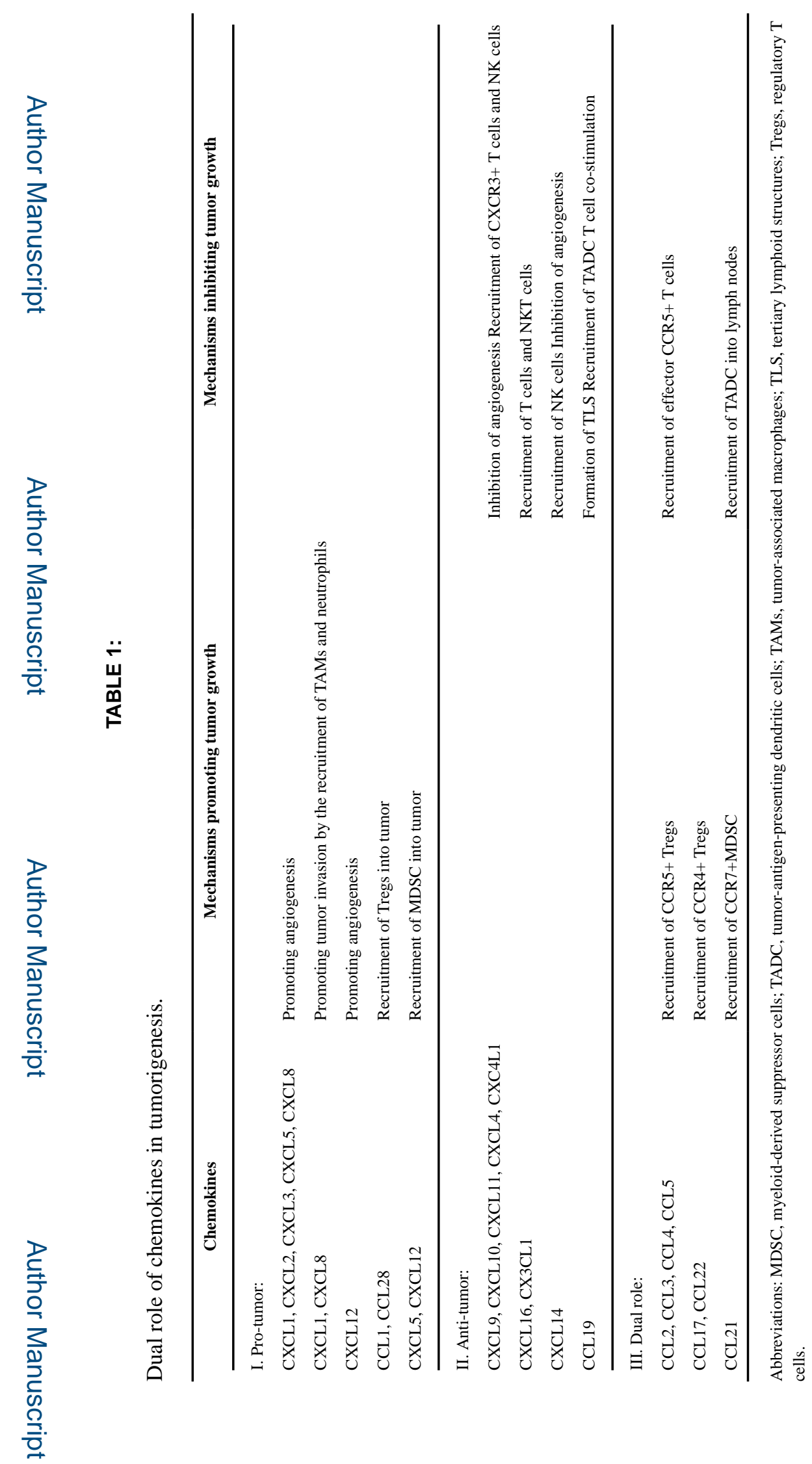

Crit Rev Immunol. Author manuscript; available in PMC 2020 April 30. 